\title{
HUBUNGAN FAMILY CENTERED CARE DENGAN DAMPAK HOSPITALISASI PADA ANAK USIA PRA SEKOLAH
}

\author{
Yusrah Taqiyah, Mutiah \\ Program Studi Ilmu Keperawatan Fakultas Kesehatan Masyarakat \\ Universitas Muslim Indonesia
}

\begin{abstract}
ABSTRAK
Hospitalisasi merupakan suatu proses keperawatan yang harus dijalani anak selama berada di rumah sakit. Bagi anak usia 3-6 tahun, hospitalisasi merupakan suatu kondisi yang tidak menyenangkan karena membuat anak mengalami perpisahan, kehilangan kendali dan cireda fisik. Oleh karena itu, dibutuhkan lingkungan yang mendukung agar mengurangi efek hospitalisasi yang mempengaruhi perkembangan anak yaitu keluarga bentuk asuhan keperawatan dengan pendekatan Family Centered Care. Tujuan penelitian ini adalah untuk mengetahui hubungan Family Centered Care dengan dampak hospitalisasi pada anak pra sekolah di Rumah Sakit Ibnu Sina Makassar. Penelitian ini adalah penelitian kuantitatif dengan menggunakan rancangan cross sectional pengambilan sampel dengan metode Purposive Sampling dengan jumlah sampel 46 keluarga pasien anak usia pra sekolah 3-6 tahun. Hasil penelitian didapatkan ada hubungan penyampaian informasi dengan dampak hospitalisasi pada anak pra sekolah dengan nilai $p=0,000$ $<$ a 0,05, ada hubungan partisipasi keluarga dengan dampak hospitalisasi pada anak pra sekolah dengan niali $p=0,004<$ a 0,05, dan ada hubungan kerjasama keluarga dan perawat dengan dampak hospitalisasi pada anak pra sekolah dengan nilai $p=0,001<\alpha 0,05$. Untuk itu perawat diharapkan perlu untuk mempertahankan penerapan Family Centered Care untuk meningkatkan pelayanan melalui asuhan keperawatan.
\end{abstract}

\section{Kata kunci : Family Centered Care, Hospitalisasi, Anak Usia Prasekolah}

\begin{abstract}
Hospital is a nursing process that must be endured for children while in hospital. For children aged 36 years, hospitalization is an unpleasant condition because it makes the child experience separation, loss of control and physical disability. Therefore, a supportive environment is needed in order to reduce the effects of hospitalization that affects child development, namely family forms of nursing care with the Family Centered Care approach. The purpose of this study was to determine the relationship of Family Centered Care with the impact of hospitalization on pre-school children in Ibnu Sina Makassar Hospital. This research is a quantitative study using a cross sectional sampling design with a purposive sampling method with a total sample of 46 families of preschool children aged 3-6 years. The results showed there is a relationship between the delivery of information with the impact of hospitalization on pre-school children with a value of $p=0,000$ $<a 0.05$, there is a relationship of family participation with the impact of hospitalization on pre-school children with the value of $p=0.004<a 0.05$, and there is a relationship family and nurse collaboration with the impact of hospitalization on pre-school children with $p=0.001<a 0.05$. For this reason nurses are expected to need to maintain the application of Family Centered Care to improve services through nursing care.
\end{abstract}

Keywords: Family Centered Care, Hospitalization, preschool age children

Alamat korespondensi : Jl.Urip Sumoharjo KM.5 Program Studi Ilmu Keperawatan Universitas Muslim Indonesia, Makassar, Sulawesi Selatan

Email : yusrah.taqiyah@umi.ac.id 


\section{PENDAHULUAN}

Anak merupakan individu yang berada dalam satu rentang perubahan perkembangan yang dimulai dari bayi hingga remaja. Masa anak merupakan masa pertumbuhan dan perkembangan yang dimulai dari bayi (0-1 tahun), usia bermain/toodler (1-3 tahun), pra sekolah (3-6 tahun), usia sekolah (6-11 tahun), hingga remaja (11-18 tahun). Rentang ini berbeda antara anak satu dengan anak yang lain mengingat latar belakang anak berbeda, pada anak terdapat rentang perubahan pertumbuhan dan perkembangan yaitu rentang cepat dan lambat. (Hidayat, 2012). Sakit didefinisikan sebagai penyakit dari tubuh atau pikiran, kondisi kesehatan yang buruk atau kondisi yang tidak sehat. Anak-anak sangat rentan terhadap krisis penyakit dan hospitalisasi. Sakit dan hospitalisasi menimbulkan krisis pada kehidupan anak. Pada proses hospitalisasi anak cenderung mengalami kecemasan karena takut terhadap lingkungan rumah sakit prosedur tindakan, perpisahan, keterbatasan privasi dan melakukan rutinitas atau bahkan kematian (Najmah, 2014).

Kecemasan merupakan perasaan paling umum yang dialami oleh pasien anak terutama anak usia sekolah. Hal-hal yang menunjukkan kecemasan anak akibat perpisahan yaitu anak merasa kesepian, bosan, isolasi, menarik diri, depresi, marah, frustasi dan bermusuhan. Ciri-ciri lain dari anak yang mengalami stres selama hospitalisasi yaitu anak menjadi tidak kooperatif, tidur tidak nyenyak dan tidak mau makan (Wong, 2009). Hospitalisasi merupakan perawatan yang dilakukan di rumah sakit dan dapat menimbulkan trauma dan stres pada klien yang baru mengalami rawat inap dirumah sakit. Hospitalisasi pada anak merupakan suatu proses yang menjadi alasan yang berencana atau darurat, mengharuskan anak untuk tinggal di rumah sakit, menjalani terapi pengobatan dan perawatan sampai pemulangannya kembali ke rumah (Supartini, 2010).

Populasi anak yang dirawat di rumah sakit menurut Wong (2001) dalam Lumiu (2013), mengalami peningkatan yang sangat dramatis. Presentase anak yang dirawat di rumah sakit saat ini menjadi masalah yang lebih serius dan kompleks dibanding pada tahun-tahun sebelumnya. Di Indonesia berdasarkan survey kesehatan ibu dan anak tahun 2012 didapatkan bahwa dari 1.425 anak mengalami dampak hospitalisasi, dan 33,2\% diantaranya mengalami dampak hospitalisasi berat, 41,6\% mengalami dampak hospitalisasi sedang, dan 25,2\% mengalami dampak hospitalisasi ringan. Di Indonesia jumlah anak usia pra sekolah (3-5 tahun). Berdasarkan Survei Ekonomi Nasional (SUSENAS) tahun 2001 sebesar 20,72\% dari jumlah total penduduk Indonesia, diperkirakan 35\% per 100 anak menjalani hospitalisasi (Sumaryoko, dalam Purwandari, 2010).

Keberadaan orang tua dapat memberikan kenyamanan bagi anak karena di rumah sakit reaksi yang muncul adalah rasa cemas, nyeri karena tindakan yang diberikan, kehilangan atau perpisahan sehingga dibutuhkan figur lekat yakni orang tua untuk berpartisipasi dalam proses perawatan anak di rumah sakit misalnya menyuapi anak saat makan, memandikan anak, memangku anak saat akan diberikan injeksi atau pemasangan infuse (Wong, 2008). Salah satu filosofi keperawatan anak adalah family centered care menekankan pentingnya keterlibatan keluarga dalam memberikan perawatan pada anak di rumah sakit (Hidayat, 2012).

Elemen penting dari family centered care adalah hubungan kerjasama yang merupakan pengembangan dari keterlibatan orang tua dan partisipasi orang tua untuk perawatan anak. (Shelton, 1987) penelitian Dunst dan Trivette (2009), menunjukan penerapan konsep Family Centered Care dalam praktik keperawatan, memperlakukan keluarga dengan penuh perhatian, menyampaikan informasi kepada keluarga agar mereka memahami tentang kondisi dan perawatan anak mereka, melibatkan partisipasi orang tua dalam pembuatan keputusan dan perawatan anak, serta kerjasama antara orang tua dan perawat. Peran orang tua dalam konsep Family Centered Care 
adalah berpartisipasi dalam proses perawatan anak di rumah sakit. Hasil penelitian terhadap 16 orang tua di china mengenai pengalaman orang tua dalam perawatan anak di rumah sakit menunjukkan bahwa keinginan orang tua untuk berpartisipasi dalam perawatan anak sangatlah besar, oleh karena itu dibutuhkan dukungan komunikasi dan emosional dari perawat selama keterlibatan mereka dalam perawatan anak di rumah sakit (Lam dkk, 2006).

\section{METODE PENELITIAN}

Penelitian ini menggunakan desain penelitian survey analitik dengan pendekatan cross sectional study yang dilaksanakan di Rumah Sakit Ibnu Sina Makassar. Metode pengambilan sampel menggunakan purposive sampling dengan jumlah sampel sebanyak 46 anak. Kriteria inklusi dalam penelitian ini adalah : Keluarga yang memiliki anak usia pra sekolah (usia 3 sampai 6 tahun) yang menjalani proses hospitalisasi di Rumah Sakit minimal selama 3×24 jam, Anak pra sekolah yang sudah melakukan pemasangan infus, Keluarga baik orang tua ataupun saudara dalam keadaan sehat jasmani dan mental, dapat berkomunikasi secara verbal ataupun lisan dan dapat membaca dan menulis.

Instrumen yang digunakan dalam penelitian ini berupa kuesioner yang terdiri atas 2 bagian, yaitu : Kuesioner Family Centered Care yang terdiri atas 34 pernyataan tertutup Kuesioner dampak hospitalisasi anak yang terdiri dari 10 pertanyaan tertutup. Pertanyaan disusun menggunakan skala Gutman (ya: 1; tidak: 0) Uji statistik yang di gunakan adalah chi square, dengn taraf signifikan yaitu a $(0,05)$.

\section{HASIL}

Karakteristik responden

Table. 1

Karakteristik Responden

\begin{tabular}{lcc}
\hline \multirow{2}{*}{ Karakteristik Responden } & \multicolumn{2}{c}{ Jumlah } \\
\cline { 2 - 3 } & $\mathbf{n}$ & $\mathbf{0}$ \\
\hline Umur & 32 & 69,6 \\
3-4 & 14 & 30,4 \\
5-6 & & \\
\hline Jenis Kelamin & 27 & 58,7 \\
Laki-laki & 19 & 41,3 \\
Perempuan & & \\
Lama Rawat & 36 & 78,3 \\
3-5 & 10 & 21,7 \\
6-8 & $\mathbf{4 6}$ & $\mathbf{1 0 0 , 0}$ \\
\hline \multicolumn{2}{c}{ Total } &
\end{tabular}

Berdasarkan tabel. 1 di atas menunjukkan umur anak terbanyak berada pada usia $3-4$ tahun yaitu sebesar $69.6 \%$ atau 32 anak, sedangkan jenis kelamin terbanyak anak - anak dengan jenis kelamin laki-laki yakni sebesar 58.7\% atau sebanyak 27 anak, dan lama rawat terbanyak selama 3 - 5 hari yaitu sebanyak $78.3 \%$ atau 36 anak. 
Tabel. 2

Hubungan Penyampaian Informasi Dengan Dampak

Hospitalisasi Pada Anak Pra Sekolah

\begin{tabular}{lccccccc}
\hline & \multicolumn{9}{c}{ Dampak Hospitalisasi } & & \\
\cline { 2 - 6 } $\begin{array}{c}\text { Penyampaian } \\
\text { Informasi }\end{array}$ & Stres & \multicolumn{2}{c}{ Tidak Stres } & Jumlah & $\begin{array}{c}\boldsymbol{P} \\
\text { Value }\end{array}$ \\
\cline { 2 - 6 } & $\mathbf{n}$ & $\mathbf{0}$ & $\mathbf{n}$ & $\mathbf{0}$ & $\mathbf{n}$ & $\mathbf{0}$ & \\
\hline Baik & 2 & 4,3 & 36 & 78,3 & 38 & 82,6 & \\
Kurang Baik & 6 & 13,0 & 2 & 4,3 & 8 & 17,4 & 0,000 \\
\hline Jumlah & $\mathbf{8}$ & $\mathbf{1 7 , 4}$ & $\mathbf{3 8}$ & $\mathbf{8 2 , 6}$ & $\mathbf{4 6}$ & $\mathbf{1 0 0 , 0}$ & \\
\hline
\end{tabular}

Berdasarkan tabel. 2 diatas menunjukkan bahwa penyampaian informasi baik didapatkan 4,3\% anak pra sekolah stres dari dampak hospitalisasi dan $78,3 \%$ anak pra sekolah tidak mengalami stress dari dampak hopitalisasi. Pada informasi kurang, diapatkan 13,0\% anak pra sekolah yang mengalami stres dari dampak hospitalisasi dan 4,3\% anak pra sekolah tidak mengalami stress atau dampak hospitalisasi. Hasil analisa data menggunakan uji chi square didapatkan hasil bahwa $p$ value = 0,000 dengan taraf signifikan ( $\alpha$ ) sebesar 0,05 maka $p<\alpha$ maka Ho ditolak, yang berarti ada hubungan antara penyampaian informasi dengan dampak hospitalisasi pada anak pra sekolah saat proses hospitalisasi di Rumah Sakit Ibnu Sina Makassar. Maka dapat diartikan semakin baik penyampaian informasi yang diberikan maka semakin kecil stres atau dampak hospitalisasi yang dialami anak saat proses hospitalisasi.

Tabel. 3

Hubungan Partisipasi Keluarga Dengan Dampak Hospitalisasi Pada Anak Pra Sekolah Di Rumah

\begin{tabular}{lccccccc}
\hline & \multicolumn{9}{c}{ Dampak Hospitalisasi } & & \\
\cline { 2 - 5 } $\begin{array}{c}\text { Partisipasi } \\
\text { keluarga }\end{array}$ & \multicolumn{2}{c}{ Stres } & \multicolumn{2}{c}{ Tidak Stres } & Jumlah & $\begin{array}{c}\boldsymbol{P} \\
\text { Value }\end{array}$ \\
\cline { 2 - 6 } & $\mathbf{n}$ & $\mathbf{0}$ & $\mathbf{n}$ & $\mathbf{0}$ & $\mathbf{n}$ & $\mathbf{0}$ & \\
\hline Aktif & 5 & 10,9 & 38 & 82,6 & 43 & 93,5 & \\
Kurang Aktif & 3 & 6,5 & 0 & 0,0 & 3 & 6,5 & 0,002 \\
Jumlah & $\mathbf{8}$ & $\mathbf{1 7 , 4 \%}$ & $\mathbf{3 8}$ & $\mathbf{8 2 , 6 \%}$ & $\mathbf{4 6}$ & $\mathbf{1 0 0 , 0}$ & \\
\hline
\end{tabular}

Berdasarkan tabel.3 diatas menunjukkan bahwa partisipasi keluarga aktif didapatkan 10,9\% anak pra sekolah mengalami stres dari dampak hospitalisasi dan $82,6 \%$ anak pra sekolah tidak stres dari dampak hospitalisasi, pada partisipasi keluarga kurang aktif didapatkan 6,5\% anak pra sekolah seluruhnya mengalami stress atau dampak hospitalisasi. Hasil analisa data menggunakan uji chi square didapatkan hasil bahwa $p$ value $=0,002$ dengan taraf signifikan ( $\alpha$ ) sebesar 0,05 maka $p<\alpha$ maka Ho ditolak, yang berarti ada hubungan antara pepartisipasi keluarga dengan dampak hospitalisasi 
pada anak pra sekolah saat proses hospitalisasi di Rumah Sakit Ibnu Sina Makassar. Maka dapat diartikan semakin aktif partisipasi keluarga yang diberikan maka semakin kecil stres atau dampak hospitalisasi yang dialami anak saat proses hospitalisasi.

Tabel. 4

Hubungan Kerjasama Keluarga Dengan Dampak Hospitalisasi Pada Anak Pra Sekolah

\begin{tabular}{|c|c|c|c|c|c|c|c|}
\hline \multirow{3}{*}{$\begin{array}{c}\text { Kerjasama } \\
\text { Keluarga }\end{array}$} & \multicolumn{4}{|c|}{ Dampak Hospitalisasi } & \multirow{2}{*}{\multicolumn{2}{|c|}{ Jumlah }} & \multirow{3}{*}{$\begin{array}{c}P \\
\text { Value }\end{array}$} \\
\hline & \multicolumn{2}{|c|}{ Stres } & \multicolumn{2}{|c|}{ Tidak Stres } & & & \\
\hline & $\mathbf{n}$ & $\%$ & $\mathbf{n}$ & $\%$ & $\mathbf{n}$ & $\%$ & \\
\hline Aktif & 4 & 8,7 & 37 & 80,4 & 41 & 89,1 & \\
\hline Kurang Aktif & 4 & 8,7 & 1 & 2,2 & 5 & 10,9 & 0,001 \\
\hline Jumlah & 8 & 17,4 & 38 & 82,6 & 46 & 100,0 & \\
\hline
\end{tabular}

Berdasarkan table. 4 diatas menunjukkan bahwa kerjasama keluarga aktif, didapatkan 8,7\% anak pra sekolah mengalami stres dari dampak hospitalisasi dan 80,4\% anak pra sekolah tidak stres dari dampak hospitalisasi, pada kerjasama keluarga kurang aktif didapatkan 8,7\% anak pra sekolah mengalami stres dari dampak hospitalisasi dan 2,2\% tidak mengalami stress atau dampak hospitalisasi. Hasil analisa data menggunakan uji chi square didapatkan hasil bahwa $p$ value $=0,001$ dengan taraf signifikan (a) sebesar 0,05 maka $p<a$ maka Ho ditolak yang berarti ada hubungan antara kerjasama keluarga dengan dampak hospitalisasi pada anak pra sekolah saat proses hospitalisasi di Rumah Sakit Ibnu Sina Makassar. Maka dapat diartikan semakin aktif kerjasama keluarga yang diberikan maka semakin kecil stres atau dampak hospitalisasi yang dialami anak saat proses hospitalisasi.

\section{PEMBAHASAN}

\section{Hubungan Penyampaian Informasi Dengan Dampak Hospitalisasi Pada Anak Pra sekolah di} Rumah Sakit Ibnu Sina Makassar

Hasil uji statistic di peroleh $p$ value $=0,000<$ a 0,05 maka Ha diterima dan Ho ditolak, artinya ada hubungan penyampaian informasi dengan dampak hospitalisasi pada anak pra sekolah yang menjalani perawatan di Rumah Sakit Ibnu Sina Makasaar. Dimana dari 46 anak sebanyak 78,3\% tidak mengalami dampak hospitalisasi karena penyampaian informasi baik.

Berdasarkan asumsi peneliti ketika melakukan penelitian di Rumah Sakit Ibnu Sina Makassar yaitu, peneliti melihat bahwa penyampain informasi kepada keluarga dari perawat sudah cukup baik, dimana perawat memperkenalkan diri kepada keluarga pasien disaat ada pasien yang baru masuk, perawat juga memberikan informasi terkait tujuan pemasangan infuse kepada keluarga saat pemasanagn infuse pada anak serta menjelaskan tentang jadwal control dokter kepada keluarga yang bersangkutan. Penyampaian informasi yang baik dari perawat memudahkan keluarga dalam berkomunikasi terkait kondisi anak mereka sehingga keluarga tidak terlalu cemas dalam menghadapi anak yang menjalani perawatan di rumah sakit. Hal ini juga di tunjang oleh tingkat pendidikan keluarga yang memiliki anak usia 3-6 tahun yang sedang menjalani perawatan 
di Rumah Sakit Ibnu Sina Makassar yakni sebanyak 34,6\% berpendidikn SMA sehingga keluarga mudah menyerap informasi mengenai perawatan anak. Penyampaian Informasi ini juga membantu keluarga untuk bersikap dan bertindak melibatkan diri dalam merawat anak agar dampak hospitalisasi pada anak dapat berkurang.

Penelitian ini sejalan dengan pendapat suriani (2011) dalam penelitianya bahwa keluarga yang berpendidikan tinggi lebih mendukung anak saat dirawat dibanding keluarga yang berpendidikn rendah. Memberikan informasi kesehatan pada keluarga tentang kondisi kesehatan anak dapat meningkatkan peran keluarga dan mengontrol perawatan anak selama hospitalisasi. Hubungan yang baik dan saling percaya antara perawat dengan keluarga dapat menimbulkan rasa nyaman dan dapat meminimalkan dampak hospitalisasi (Lory, 2011)

Informasi dapat diberikan melalui komunikasi terapeutik. Komunikasi terapeutik yang dimaksudkan antara perawat dan keluarga tidak hanya sebatas sebagai alat pembuat keputusan atau pertukaran informasi untuk melengkapi proses keperawatan tetapi kualitas, keefektifan, dan efisiensi komunikasi untuk menciptakan ekspektasi yang positif bagi perawat dan keluarga. Selain itu, kewajiban perawat dalam melakukan intervensi keperawatan mandiri atau yang didelegasikan harus menjalin dan mempertahankan hubungan saling percaya yang baik (rapport) dengan pasien. Perawat harus memastikan bahwa keluarga dan anak memperoleh informasi mengenai diagnose dan rencana tindakan, memberikan umpan balik terhadap setiap perkembangan kondisi dan menunjukkan rasa kepedulian untuk mencegah rasa ketidakberdayaan dan putus asa yang dirasakan oleh klien (fisher dkk, 2011).

Semakin baik dan semakin lengkap penyampaian informasi kesehatan yang diberikan maka dampak hospitalisasi anak akan semakin berkurang seiring bertambahnya informasi pada keluarga. Informasi yang jelas sangat penting bagi klien atau keluarga untuk mengatasi dampak hospitalisasi akibat kurangnya informasi. Tingkat dampak hospitalisasi berkurang bila diberikan informasi kesehatan dibanding dengan tidak sama sekali (Herliana, 2010).

\section{Hubungan Partisipasi Orang tua Dengan Dampak Hospitalisasi Pada Anak Pra sekolah di Rumah Sakit Ibnu Sina Makassar}

Hasil uji statistic di peroleh $p$ value $=0,002<$ a 0,05 maka Ha diterima dan Ho ditolak, artinya ada hubungan partisipasi keluarga dengan dampak hospitalisasi pada anak pra sekolah yang menjalani perawatan di Rumah Sakit Ibnu Sina Makasaar. Dimana terdapat dari 46 responden sebanyak 82,6\% anak tidak mengalami dampak hospitalisasi karena partisipasi keluarga aktif.

Berdasarkan asumsi peneliti ketika melakukan penelitian di rumah sakit Ibnu Sina Makassar yaitu, peneliti melihat bahwa keluarga cukup aktif berpartisipasi dalam pengambilan keputusan terkait perawatan yang akan diberikan kepada anak. Keluarga juga diperbolehkan untuk menanggapi masalah perawatan anak. Dengan adanya partisipasi aktif membuat keluarga merasa lebih dihargai dikarenakan keluarga ikut berpartisipasi dalam perawatan anak. Hal ini juga berdampak positif pada anak dimana sebagian besar anak yang menjalani perawatan tidak mengalami stress atau dampak hospitalisasi seperti anak tidak menagis terus menerus ketika keluarga tidak mendampingi anak saat anak akan diberikan tindakan keperawatan oleh perawat.

Davidson (2009) menjelaskan bahwa keluarga bisa berpartisipasi, mendukung dan melindungi pasien untuk mampu beradaptasi dengan kondisi pasien yang dirawat. Peran serta keluarga perlu ditingkatkan pada saat merawat anak di rumah sakit. Peran keluarga tidak bisa maksimal jika tidak didukung oleh perawat. Peran perawat dalam meminimalkan dampak 
hospitalisasi sangatlah penting. Salah satu tindakan yang penting yang dapat dilakukan untuk mengurangi dampak hospitalisasi adalah melibatkan keluarga untuk terlibat aktif dalam perawatan anak, salah satunya dengan membolehkan keluarga untuk tinggal bersama anak selama 24 jam, hal ini merupakan salah satu bagian dari pelaksanaan Family Centered Care (Supartini, 2010).

Cara untuk meminimalkan dampak negative dari hospitalisasi adalah perawat melibatkan keluarga dalam perawatan dan mendorong peran serta dalam perawatan. Penelitian yang dilakukan oleh Hallstrom \& Elender (2003) menyatakan bahwa peran serta keluarga membuat dampak hospitalisai positif pada anak karena perawat melibatkan keluarga maupun anak dalam pengembangan keputusan selama perawatan. Anak mampu mengembangkan diri sebagai pribadi dan memberikan keluarga perasaan bahwa mereka adalah bagian dari tim dalam memberikan anak perawatan secara optimal selama di rawat.

Hal ini sejalan dengan penelitian yang dilakukan oleh Ygge (2004) bahwa bentuk peran serta keluarga dalam perawatan dirumah sakit adalah keterlibatan keluarga dalam perawatan. Bentuk partisipasi keluarga dimulai membantu anak dan mendampingi anak selama prosedur perawatan. Hal ini membuat anak merasa nyaman dan tidak takut menghadapi perawat atau dokter, seperti perawat meminta pendapat keluarga dalam hal akan melalukan suatu tindakan keperawatan terhadap anak pra sekolah yang dirawat d irawat dirumah sakit.

Menurut Coyne (2006) salah satu bentuk dukungan perawat adalah dengan adanya strategi perawat untuk manajemen orang tua saat anak dirawat. Bentuk strategi tersebut adalah mensosialisasikan lingkungan rawat dan perawatan yang akan dijalani anak. Strategi yang kedua adalah memberikan kesempatan kepada orang tua untuk terlibat dalam pengambilan keputusan tindakan yang akan diterima oleh anak.

\section{Hubungan Kerjasama Orang Tua dan Perawat dengan Dampak Hospitalisasi Pada Anak Pra Sekolah Di Rumah Sakit Ibnu Sina Makassar}

Hasil uji statistic di peroleh $p$ value $=0,001<$ a 0,05 maka Ha diterima dan Ho ditolak, artinya ada hubungan kerjasama dengan dampak hospitalisasi pada anak pra sekolah yang menjalani perawatan di Rumah Sakit Ibnu Sina Makasaar. Dimana terdapat dari 46 responden sebanyak 80,4\% anak tidak mengalami dampak hospitalisasi karena kerjasama keluarga baik.

Berdasarkan asumsi peneliti ketika melakukan penelitian di rumah sakit Ibnu Sina Makassar yaitu, peneliti melihat bahwah keluarga cukup aktif dalam bekerjasama dengan perawat terkait asuhan keperwatan yang diberikan kepada anak, dimana keluarga ikut mendampingi anak saat anak akan dipasangi infuse atau diberikan suntikan, perawat juga meminta keluarga untuk melaporkan setiap perubahan kondisi anak dan selalau menanyakan kondisi anak kepada keluarag setelah pemasanagan infuse atau diberiakan suntikan. Hal ini berdampak positif pada anak dimana anak tidak mengalami stress dari dampak hospitalisasi dikarenakan keluarga bekerjasama mendampingi anak saat anak akan diberikan tindakan invasive oleh perawat.

Perawat dalam melakukan perawatan pada anak harus mempertimbangkan untuk menghadirkan keluarga pada saat dilakukan prosedur yang menimbulkan nyeri (Hidayat, 2011). Setiap asuhan pada anak yang dirawat di rumah sakit memerlukan keterlibatan keluarga. Untuk mencapai tujuan dari pencegahan dan pengobatan pada anak yang dirawat di rumah sakit, sengat diperlukan kerjasama antara tim kesehatan dan keluarga, serta asuhan pada anak yang paling baik adalah dilakukan oleh keluarga. Terbukti dalam beberapa penelitian bahwa anak akan merasa 
aman apabila berada disamping keluarganya, terlebih lagi pada saat menghadapi situasi menakutkan seperti dilakukan prosedur invasive (Supartini, 2010).

Keluarga memiliki peran yang sangat penting dalam meningkatkan kesehatan anak, menjadi perantara utama dalam perawatan langsung kepada anak, dan menyediakan akses untuk pelayanan kesehatan. Sikap dan perilaku keluarga dapat mempengaruhi kesehatan fisik dan psikologi anak. Sikap keluarga selama anak sakit, khususnya selama hospitalisasi dapat mempengaruhi ketaatan anak dalam perawatan dan dampak penyakit (Commodary, 2010). Peran keluarga yang dipaparkan oleh Chen (2005) menjelaskan bahwa bentuk peran serta keluarga selama anak dirawat di rumah sakit adalah dengan menjalin kolaborasi antara keluarga dengan profesi kesehatan dan kehadiran keluarga yang dapat memberikan rasa nyaman pada anak. Bentuk kolaborasi keluarga dan profesi kesehatan diwujudkan dengan adanya keterlibatan keluarga dalam perawatan, memberikan support emosional kepada anak, ikut terlibat pada tindakan sederhanan, menjelaskan kepada anak tentang kondisi anak dan memenuhi kebutuhan anak selama dirawat.

Menurut Hidayat (2012) Lingkungan keluarga sangat menentukan kehidupan anak, sehingga keperawatan anak harus mengenai keluarga sebagai tempat tinggal atau konstan tetap dalam kehidupan anak. Keluarga adalah unsur paling dekat dengan anak mengingat anak bagian dari keluarga. Room in atau pendamping keluarga selama menjalani perawatan di rumah sakit akan membantu meminimalkan stres yang dialami oleh anak maupun keluarga karena perpisahan (Supartini, 2010). Hal ini sejalan dengan penelitian yang dilakukan olehn Jannah miftahul (2015) bahwa ada hubungan antara peran serta orang tua terhadap tingkat kecemasan anak pada saat pemasangan infuse, dengan nilai $p=0,001<\alpha 0,05$.

Perasaan cemas merupkan dampak dari hospitalisasi yang dialami oleh anak karena menghadapi stressor yang ada dilingkungan rumah sakit. Perasaan tersebut dapat timbul karena menghadapi sesuatu yang baru dan belum pernah dialamai sebelumnya, rasa tidak nyaman dan merasakan sesuatu yang menyakitkan. Kecemasan merupakan perasaan paling umum yang dialamai oleh pasien anak terutama anak usia pra sekolah (Supartini, 2010).

\section{SIMPULAN}

Ada hubungan antara penyampaian informasi, partisipasi orang tua, dan kerjasama antara orang tua dan perawat dengan dampak hospitalisasi pada anak pra sekolah anak di Rumah Sakit Ibnu Sina Makassar .

\section{SARAN}

Diharapkan perawat mempertahankan pendekatan Family Centered Care yang telah dilakukan serta lebih menambah wawasan dan mengevaluasi aplikasi pendekatan Family Centered Care yang belum dan telah dilakukan. Bagi Rumah Sakit diharapkan untuk menyelenggarakan pelatihan untuk meningkatkan pengetahuan sikap, dan keterampilan perawat dalam melaksanakan Family Centered Care serta memotivasi perawat untuk memperhatikan peran perawat dalam memberikan asuhan keperawatan.

\section{DAFTAR PUSTAKA}

Chen, W.L. (2005) Nurse's And Parent's Attitudes Toward Pain Managemen And Parental Participation In Postoperative Care Of Children. Thesis, Centre For Research, The Queensland University Of Technology. (http:www.lifecho diakses tanggal 18 september 2019) 
Coyne, I (2006) Children's Experience Of Hospitalization Journal Of Child Healt Care

Davidson, J.E.(2009). Family Centered Care : Meeting The Needs Of Patient Families And Helping Families Adapt To Critical Ilnes. Critical Nurse,

Dunst. C, J., Trivette C.M.T. (2009). Metanalytic Struktural Equation Modeling Of The Influences Of Family Centered Care On Parent And Child Psychological Health. International Journal of Pediatrics, 1-9 (http://download.hindawi.com/journals/ijped/pdf diakses tanggal 1 juni 2019)

Fisher, M.J.,Brome, M.E. (2011) Parent Profider Communication During Hospitalization, Journal Of Pediatrics

Herliana. (2010). Hubungan Pendidikan Kesehatan Dengan Tingkat Kecemasan Pasien Pre Operasi Seksiocaesarea Di Ruang Bersalin RS Zahriah Jakarta Selatan (http://library.uprivj.ac.id/index.php?p=show_detail\&id=5606 diakses pada tanggal 18 september 2019)

Hidayat, A. A. (2012). Pengantar Ilmu Keperawatan Anak, Ed I: Jakarta, Salemba Medika.

Jannah,M (2015). Hubungan Peran Serta Orang Tua Terhadap Tingkat Kecemasan Pada Anak. (http://ppjp.unlam.ac.id/journal/index.php/JDK/article/view/717 diakses tanggal 18 september)

Lam, L, W., A, Chang, Anne M., Momssey, J. (2009). Family Centered Care For Children With Special Health Care Needs. Washington: Association for The Care of Children's Health (http://www.naemt.org/docs/defaul-source/Member-Resource

Documents/Care_of_Children_with_special_Health_Care_Needs.pdf) diakses tanggal 10 agustus 2019

Lory. (2011). Family Centered Care: Emla Cream And Application Of Heat Tofacilitate Peripheral Venous Cannulation In Children

(http://www.scribd.com/doc/129915463/Atarumatic-Care=Emla diakses tanggal 18 september 2019)

Lumiu, Stella Engel., Josef, T. (2013). Hubungan Dukungan Keluarga Dengan Tingkat Kecemasan Akibat Hospitalisasi Pada Anak di Usia Pra Sekolah. Manado: Jurnal keperawatan

(http:// ejurnal.unsrat.ac.id/index.php/jkp/article/view/2242pdf diakses pada tanggal 14 agustus 2016)

Najmah. (2014). Epidemiologi Untuk Mahasiswa Kesehatan Masyarakat. Jakarta : Rajawali Pers

Purwandari, H. (2010). Terapi Bermain Untuk Menurunkan Kecemasan Perpisahan Pada Anak Pra Sekolah yang Mengalami Hospitalisasi.

(http://jurnal.pdii.lipi.go.id/admin/2110_5259_2085_8930.pdf diakses tanggal 14 agustus 2019)

Shelton, T. L., JepPson, E. S.Johson. B.H. (2006). Family Centered Care For Children With Special Health Care Needs. Washington Association For The Care Of Children's Health.

Supartini, Yupi. (2010). Buku Ajar Konsep Dasar Keperawatan Anak. Jakarta: EGC 
Suriani. (2011) Hubungan Dukungan Keluarga Dengan Tingakt Kecemasan Hospitalisasi Pada Anak Usia Pra Sekolah Di Ruang Perawatan Anak Pivalium DII V RS TNI A.L. Dr Ramelan Kota Surabaya. (http://jurnal.ppii.lipi.go.id diakses tanggal 19 september 2019)

Wong, Donna L. (2009). Buku ajar keperawatan pedriatrik volume 1 edisi 6 jakarta : EGC

Ygg.M.B. (2004). Parental Involvement In Pediatric Care Implication For Clinical Practice And Quality Of Care. Dessertation. Departement Of Public Health And Caring Scienses,Uppsala University,Sweden. (http:// www.hsj.gr diakses tanggal 18 september 2019) 